\title{
Influencing factors for preparation of platelet-rich plasma in horses
}

\section{Fatores que influenciam o preparo do plasma rico em plaquetas na espécie equina}

\author{
Ana Carolina Barros da Rosa Pedroso1*; Andréia da Costa Peixoto1; Evelyn de \\ Oliveira ${ }^{1}$; Helena Tavares Dutra'; Roberta Carvalho Basile ${ }^{2}$; Luciana Ramos \\ Gaston Brandstetter ${ }^{3}$; Veridiana Maria Brianezi Dignani de Moura ${ }^{4}$
}

\section{Highlights}

Both protocols tested were able to sufficiently concentrate platelets.

The protocol with the higher rotational force and the longer time produced better PRP.

Other variables interfere directly with the replicability of the technique.

\begin{abstract}
There is no consensus in the literature as to the best platelet-rich plasma (PRP) acquisition method or the ideal platelet concentration to stimulate tissue repair. Besides that, most studies do not provide a clear and replicable description of the methods used, which makes standardization and result comparison difficult. Thus, this study aimed to accurately describe the method and evaluate factors influencing PRP preparation in equines. In this regard, two protocols were used, P1 and P2, based on two centrifugation methods, which differed in blood volume, speed and time, and platelet pipetting and resuspension. In conclusion, factors such as centrifugation strength and time are essential to obtain PRP with adequate platelet count. However, other factors such as tube type and plasma pipetting and resuspension methods directly interfere with the replicability of the technique, and hence influencing PRP applicability.
\end{abstract}

Key words: Platelet concentration. Double centrifugation. Standardization.

\section{Resumo}

Não há consenso na literatura quanto ao melhor método de obtenção do plasma rico em plaquetas (PRP) ou à concentração plaquetária ideal com o objetivo de estimular o reparo tecidual. Além disso, grande parte

1 Postgraduate Students at Animal Science Graduate Program, Escola de Veterinária e Zootecnia, Universidade Federal de Goiás, UFG, Goiânia, GO, Brazil. E-mail: anacarolinapedroso@ymail.com; andreiapeixoto_@hotmail.com; evelyn_oli18@hotmail.com; helenatavares21@hotmail.com

2 Profa Dra, Centro Universitário Central Paulista, UNICEP, São Carlos, SP, Brazil. E-mail: carvalho.basile@gmail.com

3 Profa Dra, Veterinary Medicine Department, Escola de Veterinária e Zootecnia, UFG, Goiânia, GO, Brazil. E-mail: lubrands@yahoo.com.br

${ }^{4}$ Profa Dra, Animal Pathology Department, Escola de Veterinária e Zootecnia, UFG, Goiânia, GO, Brazil. E-mail: vdmoura@hotmail.com

* Author for correspondence

Received: Mar. 21, 2020 - Approved: Apr. 08, 2021 
dos trabalhos não faz descrição clara e reprodutível dos métodos utilizados, o que dificulta a padronização e a comparação dos resultados. Dessa forma, este trabalho teve por objetivo descrever detalhadamente a metodologia e avaliar fatores que influenciam o preparo do PRP em equinos. Para isso, foram utilizados dois protocolos, P1 e P2, baseados em duas centrifugações, que diferiram quanto ao volume de sangue colhido, velocidade e tempo das centrifugações e método de pipetagem e ressuspensão das plaquetas. Conclui-se que fatores como força e tempo de centrifugação são essenciais à obtenção de um PRP com concentração plaquetária adequada. Contudo, fatores adicionais como tipo de tubo e métodos de pipetagem e ressuspensão do plasma interferem diretamente na repetibilidade da técnica, influenciando a aplicabilidade prática do PRP.

Palavras-chave: Concentração plaquetária. Dupla centrifugação. Padronização.

\section{Introduction}

Platelets are small discoid blood cells formed from megakaryocytes in the bone marrow and have two types of intracellular granules. Dense granules store adenosine diphosphate (ADP), adenosine triphosphate (ATP), serotonin and calcium, while $\alpha$-granules store coagulation factors, growth factors and other proteins (Zucker-Franklin, 1996). At latency, platelets are not thrombogenic and require stimulation for activation, which can occur from their contact with collagen. Once activated, they morphologically alter and develop pseudopods, which promote platelet aggregation and granule content release (Everts et al., 2006). These cells play a primordial role in haemostasis, in addition to being considered sentinel immune cells that assist initiation and organization of inflammatory events (Herter, Rossaint, \& Zarbock, 2014).

Plasma rich in platelets (PRP) is an autologous plasma preparation, enriched with a higher platelet concentration than that of the whole blood (Malanga \& Goldin, 2014). Most PRP acquisition methods are based in one or two centrifugations of autologous blood collected with anticoagulant (Davis et al., 2014). Its therapeutic potential relies on platelet capability of releasing and supplying supraphysiological amounts of growth factors and cytokines that, in turn, promote regenerative stimulus and help in tissue repair by scarring (Peter, Wu, Diaz, \& Borg-Stein, 2016).

The first reports of PRP clinical use date from the 1980s, in cardiothoracic and maxillofacial surgeries (Ferrari et al., 1987). Currently, it has been reported in other fields such as plastic surgery, orthopaedics, and sports medicine (Nguyen, BorgStein, \& Mclnnis, 2011). In animal models, PRP has been used in studies involving cornea neovascularization, conjunctive tissue regeneration, and surgical wounds reepitalization (Lima, 2009). In equines, PRP has been researched since the beginning of 2000 in wound treatments, tendinitis, desmitis, osteoarthritis, and fracture consolidation (Pereira et al., 2013).

PRP acquisition methods consist of whole blood centrifugation, aiming to concentrate platelets and reduce red blood cells and leukocytes (Sampson, Gerhardt, \& Mandelbaum, 2008). There is vast literature about PRP; however, studies are distinct 
regarding the applied method in its acquisition. Thus, there is difficulty in creating technical standards in newstudiesand result comparison (DeLong, Russell, \& Mazzocca, 2012). Two main challenges for PRP standardization are the individual peripheral blood variation concerning platelet concentration and growth factors, and the several preparation stages (Dragoo, Wasterlain, Braun, \& Nead, 2014).

Most studies describe PRP acquisition method only in relation to the number and time of centrifugations, while the g-force, which is the force exerted on spinner rotor, is calculated based on its radius and spin speed. Details regarding blood collection, sample conditioning, and plasma pipetting after centrifugation are almost always omitted. In a review of 105 clinical studies on PRP use in musculoskeletal disorders treatment, only 11 (10\%) provided a clear and replicable protocol description, and 17 (16\%) provided quantitative measurements of the final product composition (Chahla et al., 2017). Thus, given the inconsistency in PRP preparation methods, there is no consensus on the best protocol. In this context, this study aimed to describe the method in detail and to evaluate factors influencing PRP preparation in equines.

\section{Material and Methods}

All procedures involving animals in this study were approved by the Animal Use Ethics Committee of the Federal University of Goiás, CEUA/UFG (protocol number 074/2016). Twenty-one healthy horses, of different breeds, aged between three and 18 years old, and with an average weight of $350 \mathrm{~kg}$ were used. Two protocols (P1 and $\mathrm{P} 2$ ) were tested to obtain PRP, both adapted from Carmona (2006).
For P1, samples of blood from eight animals were aseptically collected by jugular puncture with a $21 \mathrm{G}$ needle and vacutainer glass tubes containing $3.2 \%$ sodium citrate $\left(\mathrm{BD}^{\circledR}\right)$. Five $4.5-\mathrm{mL}$ tubes were filled, totalling $22.5 \mathrm{~mL}$ blood from each animal. The tubes were homogenized and, after 10 minutes, a period for natural red blood cell sedimentation, were centrifuged for one minute, at low rotation (900 rpm). Plasma remaining in the upper portion of tubes was transferred to a single 10-mL non-anticoagulant glass tube. The transfer was performed with the aid of an automatic pipette with a minimum capacity of $100 \mu \mathrm{L}$ and a maximum of $1000 \mu \mathrm{L}$ and a plastic tip with equivalent capacity, being careful not to capture buffy coat zone cells, whitish layer between red blood cells and plasma. Pipetting was always performed by the same operator. The plasma containing tube was centrifuged again for five minutes at $1800 \mathrm{rpm}$. Then, about $60 \%$ of the upper plasma, defined as platelet-poor plasma (PPP), was pipetted and discarded. The remaining portion of the PRP tube was protected from light and kept for 30 minutes in an automatic haematological homogenizer (Nihon Kohden Celltac Alpha ${ }^{\circledR}$ ) for platelet counting.

For protocol P2, samples of blood from thirteen animals were collected aseptically by jugular puncture with $21 \mathrm{G}$ needle and vacutainer glass tubes containing $3.2 \%$ sodium citrate (BD $\left.{ }^{\circledR}\right)$. Twenty-four $4.5-\mathrm{mL}$ tubes were filled, totalling $108 \mathrm{~mL}$ blood from each animal. Tubes were homogenized manually until their first centrifugation, performed at $1000 \mathrm{rpm}$ for 10 minutes. In a laminar flow fume hood, with the aid of a $14 \mathrm{G}$ peripheral intravenous catheter and $10 \mathrm{~mL}$ disposable syringe, the supernatant plasma was collected. At this stage, the tube wall 
was gently scraped with the catheter needle while aspirating with the syringe to collect platelets that might have adhered there after the first centrifugation. Supernatant plasma was collected and transferred to $10-\mathrm{mL}$ nonanticoagulant plastic tubes (Biocon ${ }^{\circledR}$ ), being careful not to capture cells from the buffy coat zone. Plasma transfer was always performed by the same operator. Then, the new tubes were centrifuged at 4000 rpm for 10 minutes. After the second centrifugation, about $80 \%$ of plasma was discarded (PPP) and the remaining fraction (PRP) was homogenized for 30 seconds in a vortex shaker and transferred to a sterile syringe with an $18 \mathrm{G}$ spinal needle. A fraction of the final product was reserved for platelet counting.

In both protocols, a fraction of the whole blood was separated to obtain baseline platelet values, red blood cells, and leukocytes. Whole blood and PRP platelet counts obtained in $\mathrm{P} 1$ and $\mathrm{P} 2$ were performed on an automated haematology analyser (Nihon Kohden Celltac Alpha ${ }^{\circledR}$.

Statistical analysis was conducted in a quantitative form, calculating means and standard deviations of the platelet concentrations acquired in $\mathrm{P} 1$ and $\mathrm{P} 2$. Thereafter, the t-Student test was performed to compare means between groups. Statistical difference was considered when $p<0.05$. Data were analysed using the Excel software.

\section{Results and discussion}

PRP production is based on two principles, including the formation of a density gradient of blood constituents by centrifugation, and creation of a product with altered blood component concentrations by selectively collecting a fraction of the density gradient previously formed (Delong et al., 2011). Although most studies describe PRP acquisition as of easy execution and replicability (Pereira etal., 2013), our experience in this study is in accordance with Michelson (2007), who stated that the preparation of this product seems to be considerably delicate and dependent on a series of variables.

Both protocols were able to sufficiently concentrate platelets. However, in P1, this result was achieved in only one of eight animals in the first preparation attempt. In five animals, two attempts were necessary, and in the other two animals, three attempts were necessary to recover a minimum platelet increment of two times. In protocol P2, platelet concentration was recovered in the first attempt in all animals.

Whole blood and PRP platelet count from protocols $\mathrm{P} 1$ and $\mathrm{P} 2$ are described in Table 1. Platelet increment was calculated by the ratio between PRP platelet count and the whole blood platelet count of the same animal. Thus, the number of times the PRP platelet concentration was higher than that of whole blood was obtained. 
Table 1

Platelet counts (x 103/ $\mathrm{\mu l}$ ) of whole blood (WB) and platelet-rich plasma (PRP) recovered by protocols P1 and $\mathrm{P} 2$, with their respective platelet increments in relation to the basal value of each animal

\begin{tabular}{|cccccccc}
\hline & \multicolumn{2}{c}{ Protocol 1 } & \multicolumn{4}{c|}{ Protocol 1 } \\
\hline Animal & WB & PRP & $\begin{array}{c}\text { Platelet } \\
\text { increment }\end{array}$ & Animal & WB & PRP & $\begin{array}{c}\text { Platelet } \\
\text { increment }\end{array}$ \\
\hline P1A1 & 103 & 326 & 3,17 & P2A1 & 178 & 713 & 4,01 \\
P1A2 & 120 & 325 & 2,71 & P2A2 & 94 & 501 & 5,33 \\
P1A3 & 125 & 411 & 3,29 & P2A3 & 186 & 1241 & 6,67 \\
P1A4 & 132 & 564 & 4,27 & P2A4 & 89 & 1171 & 13,16 \\
P1A5 & 161 & 514 & 3,19 & P2A5 & 133 & 931 & 7,00 \\
P1A6 & 100 & 412 & 4,12 & P2A6 & 143 & 389 & 2,72 \\
P1A7 & 114 & 349 & 3,06 & P2A7 & 167 & 569 & 3,41 \\
P1A8 & 132 & 270 & 2,05 & P2A8 & 200 & 410 & 2,05 \\
& & & & P2A9 & 196 & 380 & 1,94 \\
& & & & P2A10 & 104 & 1033 & 9,93 \\
& & & & P2A11 & 139 & 579 & 4,17 \\
& & & & P2A12 & 107 & 309 & 2,89 \\
& & & & P2A13 & 108 & 409 & 3,79
\end{tabular}

$\mathrm{P} 1$ and $\mathrm{P} 2$ protocols recovered plasma with concentrated platelets, on average 3.24and 5.16-times above baseline, respectively. $\mathrm{P} 1$ resulted in greater uniformity between the products recovered from different animals (standard deviation $=0.67$ ), while $\mathrm{P} 2$ recovered PRP with great variation between individuals (standard deviation $=3.17$ ). P2 protocol recovered, on average, a higher platelet concentration, although both protocols are statistically similar (Table 2).

Tube material and needle calibre used in blood collection seem to influence PRP. According to some authors, glass tubes coated with silicone are better than polypropylene tubes. On the other hand, when not coated with silicone, glass tubes can prematurely activate platelets, influencing the final platelet count (Michelson, 2007). However, in this study, there was no change in final platelet count when using glass tubes not coated with silicone, which might have been due to the scraping of tube wall while plasma pipetting after the first centrifugation. Yet, in previous experiments, we did not obtain satisfactory results with polypropylene tubes, presenting platelet aggregation and decrease in platelet numbers in the final counting. Regarding needle calibre, the use of needles with calibres above 22G (Dhurat \& Sukesh, 2014) has been prescribed in the literature, which was performed with success in both tested protocols in our study. 


\section{Table 2}

Mean, variance, standard deviation, and PRP platelet increment statistical analysis recovered from protocols $\mathrm{P} 1$ and $\mathrm{P} 2$, in relation to the baseline value

\begin{tabular}{ccc|}
\hline & P1 & P2 \\
\hline Mean & $3.24 a$ & $5.16 a$ \\
Variance & 0.44 & 10.90 \\
\hline Standard deviation & 0.67 & 3.17
\end{tabular}

Different letters within the same line differ from each other by the Student's t-test $(P<0.05)$.

The number and speed of centrifugations directly influence final platelet concentration and can result in morphological changes in platelets, which leads to their aggregation (Michelson, 2007). Researchers compared seven protocols for PRP acquisition in equine species and concluded that the higher the g-force and centrifugation time, the higher the final product platelet concentration (Pereira et al., 2013). This information corroborates the results of the current study, in which the protocol with the higher rotational force for a longer time, in the two centrifugations (P2), acquired PRP with higher platelet concentrations, on average.

According to the literature, changes in basal blood platelet counts of each individual also influences the final platelet concentration in PRP (Michelson, 2007; Vendruscolo et al., 2012). However, our results show a lack of positive correlation between basal platelet counts and PRP platelet counts, since even individuals with lower baseline values produced PRP with high platelet concentrations when using $\mathrm{P} 1$ and $\mathrm{P} 2$ protocols.

A variable that seems extremely important but overlooked in PRP protocols is plasma pipetting process after the first blood centrifugation. Most protocols recommend total plasma volume transfer immediately above the buffy coat zone to a new tube (Vendruscolo et al., 2012; Pereira et al., 2013); however, a more detailed description is still required. In this context, this study found that plasma transfer using an automatic pipette and plastic tip, as performed in P1, does not allow total plasma removal without contamination by leukocyte and red blood cells. On the other hand, in P2, when the transfer was performed with the aid of a $14 \mathrm{G}$ peripheral intravenous catheter needle and a 10-mL syringe, plasma withdrawal was of higher precision and lower contamination index. Besides, some platelet aggregates were deposited on the tube wall after the first centrifugation, and by scraping with the catheter needle, these aggregates were again diluted in plasma.

The expected therapeutic effect of PRP is based on the release of growth factors by platelets and their binding to their respective receptors without saturation, triggering proliferative tissue response (Delong et al., 2011). Based on the studies available in the literature, it is inferred that a two to fourfold increase in platelet numbers in PRP relative to whole blood is suitable (Marx et al., 1998; Marx, 2001; Anitua et al., 2005; Graziani et al., 2006; Sánchez et al., 2007; Anitua et al., 2008; Sánchez et al., 2010; Redler, Thompson, Hsu, Ahmad, \& Levine, 2011; Torricelli et al., 
2011). Conversely, increases of less than two times do not allow expected cellular response (Haynesworth, Kadiyala, Liang, \& Bruder, 2002), while increases of four to six times produce controversial results (Haynesworth et al., 2002; Schlegel, Kloss, Schultze-Mosgau, Neukam, \& Wiltfang, 2003; Giusti et al., 2009; Broggini etal., 2011). However, increases over six times can lead to apoptosis, reduction in growth factor receptors and their desensitization (Gruber Varga, Fischer, \& Watzek, 2002; Haynesworth et al., 2002; Weibrich, Hansen, Kleis, Buch, \& Hitzler, 2004; Choi et al., 2005).

In this regard, the two protocols tested in this study were able to concentrate platelets in the final product. In P1, however, the concentration was obtained in most animals after two to three attempts, and in P2, it was obtained always at first. Moreover, the mean platelet count obtained in $\mathrm{P} 2$ was higher than in $\mathrm{P} 1$, and even within the controversial range (5.16 times above baseline), there is dilution possibility, final platelet concentration adjustment, and PRP use from platelet-poor plasma (PPP) (Fusegawa, Goto, Handa, Kawada, \& Ando, 1999; Cattaneo, Lecchi, Zighetti, \& Lussana, 2007; Ljungkvist, Olofsson, Funding, Berntorp, \& Zetterberg, 2019), while nonconcentrated $\mathrm{P} 1$ samples had to be discarded.

Changes in platelet count methods also represent a problem for standardization of PRP acquisition method and comparison between studies. Most studies use automatic haematology counters to perform blood component counts; however, it should be taken into account that when there are platelet aggregates, the equipment considers the aggregate as a single platelet. Thus, it is recommended that the sample be agitated in a haematological tube homogenizer for at least five minutes, immediately before counting, so that platelets are suspended and disaggregated (Woodell-May, Ridderman, Swift, \& Higgins, 2005). In this study, P2 samples were homogenized in a vortex shaker for 30 seconds and $\mathrm{P} 1$ samples in a haematological homogenizer for 30 minutes, which might have improved resuspension in a shorter time and reflected higher $\mathrm{P} 2$ platelet concentration than that of $\mathrm{P} 1$, having the highest homogenizing power of the vortex stirrer.

\section{Conclusion}

Factors such as centrifugation force and time are essential to obtain PRP with a suitable platelet concentration. However, other factors such as tube type and plasma pipetting and resuspension methods interfere directly with the replicability of the technique, influencing PRP applicability.

\section{Bioethics and biossecurity committee approval}

All procedures, treatments and animal care were in compliance with the Ethics Committee on Animal Use of the Federal University of Goiás (CEUA/UFG) (process 074/2016).

\section{Declaration of conflicting interests}

We have no conflict of interest to declare.

\section{Authors' Contributions}

Ana Carolina Barros da Rosa Pedroso: responsible for conducting the experiment, 
obtaining and analyzing the data and writing the article. Andréia da Costa Peixoto: responsible for conducting the experiment, obtaining and analyzing the data. Evelyn de Oliveira: responsible for conducting the laboratorial analysis of the experiment. Helena Tavares Dutra: responsible for conducting the experiment, obtaining and analyzing the data. Roberta Carvalho Basile: responsible for the elaboration of methodology and review of the article. Luciana Ramos Gaston Brandstetter: responsible for guidance during experiment and review of article. Veridiana Maria Brianezi Dignani de Moura: responsible for guidance during experiment, analysis of the microscopic variables and review of article.

\section{References}

Anitua, E., Andí, I., Sanchez, M., Azofra, J., del Mar Zalduendo, M., de la Fuente, M., \& Nurden, A. T. (2005). Autologous preparations rich in growth factors promote proliferation and induce VEGF and HGF production by human tendon cells in culture. Journal of Orthopaedic Research, 23(2), 281-286. doi: 10.1016/j.orthres.2004.08.015

Anitua, E., Aguirre, J. J., Algorta, J., Ayerdi, E., Cabezas, A. I., Orive, G., \& Andia, I. (2008). Effectiveness of autologous preparation rich in growth factors for the treatment of chronic cutaneous ulcers. Journal of Biomedical Materials Research Part B: Applied Biomaterials: An Official Journal of The Society for Biomaterials, The Japanese Society for Biomaterials, and The Australian Society for Biomaterials and the Korean Society for Biomaterials, 84(2), 415-421. doi: 10.1002/jbm.b.30886
Broggini, N., Hofstetter, W., Hunziker, E., Bosshardt, D. D., Bornstein, M. M., Seto, I., \& Buser, D. (2011). The influence of PRP on early bone formation in membrane protected defects. A histological and histomorphometric study in the rabbit calvaria. Clinical Implant Dentistry and Related Research, 13(1), 1-12. doi: 10.11 11/j.1708-8208.2009.00266.x

Carmona, J. (2006). Use of autologous platelet concentrates for the treatment of musculoskeletal injuries in the horse. Doctoral thesis en Medicina y Sanidad Animales, Universitat Autonoma de Barcelona. Barcelona, Espanha.

Cattaneo, M., Lecchi, A., Zighetti, M. L., \& Lussana, F. (2007). Platelet aggregation studies: autologous platelet-poor plasma inhibits platelet aggregation when added to platelet-rich plasma to normalize platelet count. Haematologica, 92(5), 694697. doi: 10.3324/haematol.10999

Chahla, J., Cinque, M. E., Piuzzi, N. S., Mannava, S., Geeslin, A. G., Murray, I. R., \& LaPrade, R. F. (2017). A call for standardization in platelet-rich plasma preparation protocols and composition reporting: a systematic review of the clinical orthopaedic literature. JBJS, 99(20), 1769-1779. doi: 10.2106/JBJS.16. 01374

Choi, B. H., Zhu, S. J., Kim, B. Y., Huh, J. Y., Lee, S. H., \& Jung, J. H. (2005). Effect of plateletrich plasma (PRP) concentration on the viability and proliferation of alveolar bone cells: an in vitro study. International Journal of Oral and Maxillofacial Surgery, 34(4), 420-424. doi: 10.1016/j.ijom.2004.10. 018

Davis, V. L., Abukabda, A. B., Radio, N. M., WittEnderby, P. A., Clafshenkel, W. P., Cairone, J. V., \& Rutkowski, J. L. (2014). Platelet-rich 
preparations to improve healing. Part I: workable options for every size practice. Journal of Oral Implantology, 40(4), 500510. doi: 10.1563/AAID-JOI-D-12-00104

DeLong, J. M., Beitzel, K., Mazzocca, A. D., Shepard, D., Roller, B. L., \& Hanypsiak, B. T. (2011). Update on platelet-rich plasma. Current Orthopaedic Practice, 22(6), 514523. doi: 10.1097/BCO.0b013e31823bd55

DeLong, J. M., Russell, R. P., \& Mazzocca, A. D. (2012). Platelet-rich plasma: the PAW classification system. Arthroscopy: The Journal of Arthroscopic \& Related Surgery, 28(7), 998-1009. doi: 10.1016/j. arthro.2012.04.148

Dhurat, R., \& Sukesh, M. S. (2014). Principles and methods of preparation of plateletrich plasma: a review and author's perspective. Journal of Cutaneous and Aesthetic Surgery, 7(4), 189. doi: 10.41 03/0974-2077.150734

Dragoo, J. L., Wasterlain, A. S., Braun, H. J., \& Nead, K. T. (2014). Platelet-rich plasma as a treatment for patellar tendinopathy: a double-blind, randomized controlled trial. The American Journal of Sports Medicine, 42(3), 610-618. doi: $10.1177 / 0363546513518416$

Everts, P. A., Knape, J. T., Weibrich, G., Schönberger, J. P., Hoffmann, J., Overdevest, E. P., \& van Zundert, A. (2006). Platelet-rich plasma and platelet gel: a review. The Journal of ExtraCorporeal Technology, 38(2), 174. PMCID: PMC4680757

Ferrari, M., Zia, S., Valbonesi, M., Henriquet, F., Venere, G., Spagnolo, S., \& Panzani, I. (1987). A new technique for hemodilution, preparation of autologous platelet-rich plasma and intraoperative blood salvage in cardiac surgery. The International Journal of Artificial Organs, 10(1), 47-50. doi: $10.1177 / 039139888701000111$

Fusegawa, Y., Goto, S., Handa, S., Kawada, T., \& Ando, Y. (1999). Platelet spontaneous aggregation in platelet-rich plasma is increased in habitual smokers. Thrombosis Research, 93(6), 271-278. doi: 10.1016/s0049-3848(98)001'84-4

Giusti, I., Rughetti, A., D'Ascenzo, S., Millimaggi, D., Pavan, A., Dell'Orso, L., \& Dolo, V. (2009). Identification of an optimal concentration of platelet gel for promoting angiogenesis in human endothelial cells. Transfusion, 49(4), 771-778. doi: 10.1111/j.1537-2995. 2008.02033.x

Graziani, F., Ivanovski, S., Cei, S., Ducci, F., Tonetti, M., \& Gabriele, M. (2006). The in vitro effect of different PRP concentrations on osteoblasts and fibroblasts. Clinical Oral Implants Research, 17(2), 212-219. doi: 10.1111/j.1600-0501.2005.01203.x

Gruber, R., Varga, F., Fischer, M. B., \& Watzek, G. (2002). Platelets stimulate proliferation of bone cells: involvement of platelet derived growth factor, microparticles and membranes. Clinical Oral Implants Research, 13(5), 529-535. doi: 10.1034/j. 1600-0501.2002.130513.x

Haynesworth, S. E., Kadiyala, S., Liang, L. N., \& Bruder, S. P. (2002). Mitogenic stimulation of human mesenchymal stem cells by platelet release suggest a mechanism for enhancement of bone repair by platelet concentrates. Proceeding of the Meeting of the Orthopedic Research Society, Boston, MA, USA, 48. 
Herter, J. M., Rossaint, J., \& Zarbock, A. (2014). Platelets in inflammation and immunity. Journal of Thrombosis and Haemostasis, 12(11), 1764-1775. doi: 10.1111/jth.12730

Lima, F. L. M. (2009). Efeitos do plasma rico em plaquetas no processo de reparação de feridas dérmicas padronizadas em ratos. Tese de doutorado em Ciências Odontológicas, Universidade de São Paulo, São Paulo. doi: 10.11606/T.23.2009. tde-19122009-114243

Ljungkvist, M., Olofsson, H., Funding, E., Berntorp, E., \& Zetterberg, E. (2019). Coagulation factor VIII is vital for increasing global coagulation after physical exercise. Haemophilia, 25(2), e86-e93. doi: 10.11 11/hae.13652

Malanga, G. A., \& Goldin, M. (2014). PRP: review of the current evidence for musculoskeletal conditions. Current Physical Medicine and Rehabilitation Reports, 2(1), 1-15. doi: 10.1007/s40141013-0039-5

Marx, R. E. (2001). Platelet-rich plasma (PRP): what is PRP and what is not PRP?. Implant Dentistry, 10(4), 225-228. doi: 10. 1097/00008505-200110000-00002

Marx, R. E., Carlson, E. R., Eichstaedt, R. M., Schimmele, S. R., Strauss, J. E., \& Georgeff, K. R. (1998). Platelet-rich plasma: growth factor enhancement for bone grafts. Oral Surgery, Oral Medicine, Oral Pathology, Oral Radiology, and Endodontology, 85(6), 638-646. doi: 10.1016/s1079-2104 (98)90029-4

Michelson, A. (2007). Platelets. San Diego: Elsevier/Academic Press.

Nguyen, R. T., Borg-Stein, J., \& Mclnnis, K. (2011). Applications of platelet-rich plasma in musculoskeletal and sports medicine: an evidence-based approach. PM\&R, 3(3), 226-250. doi: 10.1016/j.pmrj. 2010.11. 007

Pereira, R. C. F., Zacarias, G. V. F., Cantarelli, C., Corrêa, M. M. B., Silva, G. B. da, Barbosa, A. L. T., \& De La Côrte, F. D. (2013). Avaliação de sete protocolos para obtenção de plasma rico em plaquetas na espécie equina. Ciência Rural, 43(6), 1122-1127. doi: 10. 1590/S0103-84782013005000052

Peter, I., Wu, K., Diaz, R., \& Borg-Stein, J. (2016). Platelet-rich plasma. Physical Medicine and Rehabilitation Clinics, 27(4), 825-853. doi: 10.1016/j.pmr.2016.06.002

Redler, L. H., Thompson, S. A., Hsu, S. H., Ahmad, C. S., \& Levine, W. N. (2011). Platelet-rich plasma therapy: a systematic literature review and evidence for clinical use. The Physician and Sportsmedicine, 39(1), 4251. doi: 10.3810/psm.2011.02.1861

Sampson, S., Gerhardt, M., \& Mandelbaum, B. (2008). Platelet rich plasma injection grafts for musculoskeletal injuries: a review. Current Reviews in Musculoskeletal Medicine, 1(3-4), 165-174. doi: 10.1007/ s12178-008-9032-5

Sánchez, M., Anitua, E., Azofra, J., Andía, I., Padilla, S., \& Mujika, I. (2007). Comparison of surgically repaired Achilles tendon tears using platelet-rich fibrin matrices. The American Journal of Sports Medicine, 35(2), 245-251. doi: $10.1177 / 0363546506294078$

Sánchez, M., Anitua, E., Azofra, J., Prado, R., Muruzabal, F., \& Andia, I. (2010). Ligamentization of tendon grafts treated with an endogenous preparation rich in growth factors: gross morphology and 
histology. Arthroscopy: The Journal of Arthroscopic \& Related Surgery, 26(4), 470-480. doi: 10.1016/j.arthro.2009.08. 019

Schlegel, K. A., Kloss, F. R., Schultze-Mosgau, S., Neukam, F. W., \& Wiltfang, J. (2003). Osseous defect regeneration using autogenous bone alone or combined with Biogran or Algipore with and without added thrombocytes. A microradiologic evaluation. Mund-, Kiefer-und Gesichtschirurgie: MKG, 7(2), 112-118. doi: 10.1007/s10006-003-0454-3

Torricelli, P., Fini, M., Filardo, G., Tschon, M., Pischedda, M., Pacorini, A., \& Giardino, R. (2011). Regenerative medicine for the treatment of musculoskeletal overuse injuries in competition horses. International Orthopaedics, 35(10), 15691576. doi: 10.1007/s00264-011-1237-3

Vendruscolo, C. P., Carvalho, A. D. M., Moraes, L. F., Maia, L., Queiroz, D. L., Watanabe, M. J.,... Alves, A. L. G. (2012). Avaliação da eficácia de diferentes protocolos de preparo do Plasma Rico em Plaquetas para uso em Medicina Equina. Pesquisa Veterinária Brasileira, 32(2), 106-110. doi: 10.1590/S0100-736X2012000200002

Weibrich, G., Hansen, T., Kleis, W., Buch, R., \& Hitzler, W. E. (2004). Effect of platelet concentration in platelet-rich plasma on peri-implant bone regeneration. Bone, 34(4), 665-671. doi: 10.1016/j.bone.2003. 12.010

Woodell-May, J. E., Ridderman, D. N., Swift, M. J., \& Higgins, J. (2005). Producing accurate platelet counts for platelet rich plasma: validation of a hematology analyzer and preparation techniques for counting. Journal of Craniofacial Surgery, 16(5), 749-756. doi: 10.1097/01. scs.0000180007.30115.fa

Zucker-Franklin, D. (1996). Megakaryocyte and platelet structure in thrombocytopoiesis: the effect of cytokines. Stem Cells, 14(S1), 1-17. doi: 10.1002/stem.5530140702 
